\title{
The usefulness of modified national early warning score with the age level in critically ill medical patients
}

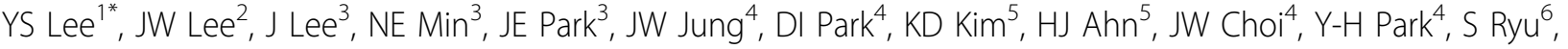 \\ WJ Jeong ${ }^{6}$, JY Moon ${ }^{4}$
}

From ESICM LIVES 2015

Berlin, Germany. 3-7 October 2015

\section{Introduction}

Early warning scores are recommended as a part of the early identification and intervention to patient deterioration. The National Early Warning Score (NEWS) allows early recognition of patient deterioration, and has the role of prognostic predictor. In addition, age is the most important factor to influence the mortality and prognosis in inpatients.

\section{Objectives}

To investigate whether the predictive value of the NEWS could be improved by including the factor of age, and to compare the modified NEWS with the pre-existing NEWS system.

\section{Methods}

This is a retrospective study on 1558 patients, who were screened by NEWS during admission period, between December, 2013 and March, 2014. The score of modified NEWS was NEWS plus the score of age level. The score of age level was defined as follows: $10-19$ years, 1 point, 20-29 years, 2 points,; 30-39 years, 3 points; $40-49$ years, 4 points; $50-59$ years, 5 points; $60-69$ years, 6 points; 70-79 years, 7 points; $80-89$ years, 8 points; $90-99$ years, 9 points. We analysed hospital mortality, 30 day mortality, 90 day mortality, and intensive care unit (ICU) admission as endopoints for identifying the predictive value of the modified NEWS. The correlation between APACHE II score and modified NEWS in patients, who were transferred to the ICU, was also analysed. Logistic regression analysis

\footnotetext{
${ }^{1}$ Severance Hospital, Yonsei University College of Medicine, Division of Pulmonology, Department of Internal Medicine, Seoul, Korea, Republic of Korea

Full list of author information is available at the end of the article
}

was performed to identify important factors for predicting hospital mortality.

\section{Results}

The median age was 63 years old and $57.2 \%$ of the patients were male. The median score of modified NEWS was six and $4.8 \%$ of the patients were transferred to the ICU during screening. The modified NEWS was better than NEWS to predict hospital mortality, 30 day mortality, 90 day mortality, and ICU admission (area under the receiver operating characteristic curve, 0.808 vs. 0.795 in hospital mortality; 0.710 vs. 0.643 in 30 day mortality; 0.686 vs. 0.655 in 90 day mortality; 0.774 vs. 0.765 in unanticipated ICU admission). In multivariate logistic regression, the odds ratio of modified NEWS were 1.3 (95\% confidence interval 1.16-1.39. $\mathrm{p}<0.001$ ) in all individuals with hospital mortality. In addition, modified NEWS correlated significantly with APACHE II score $(r=0.420$, $\mathrm{p}<0.001)$ in patients, who were transferred to the ICU.

\section{Conclusions}

The predictive power of the modified NEWS for prognosis was better than that of NEWS. More studies on larger numbers of the patients are warranted.

\footnotetext{
Authors' details

'Severance Hospital, Yonsei University College of Medicine, Division of Pulmonology, Department of Internal Medicine, Seoul, Korea, Republic of Korea. ${ }^{2}$ Chungnam National University Hospital, Daejeon Regional Emergency Center, Daejeon, Korea, Republic of Korea. ${ }^{3}$ Chungnam National University Hospital, Division of Intensive Care Units, Department of Nursing Care, Daejeon, Korea, Republic of Korea. ${ }^{4}$ Chungnam National University Hospital, Division of Pulmonary and Critical Care Medicine, Department of Internal Medicine, Daejeon, Korea, Republic of Korea. ${ }^{5}$ Daejeon Sun-Hospital, Department of Emergency Medicine, Daejeon, Korea, Republic of Korea.
}

(c) 2015 Lee et al.; This is an Open Access article distributed under the terms of the Creative Commons Attribution License (http:// creativecommons.org/licenses/by/4.0), which permits unrestricted use, distribution, and reproduction in any medium, provided the original work is properly cited. 
Published: 1 October 2015

\section{References}

1. Smith $G B$, et al: The abilityof the national early warning score to discriminate patients at risk of early cardiac arrest, unanticipated intensive care unit admission, and death. Resuscitation 2013, 84:465.

2. Jo $S$, et al: Comparison of the trauma and injury severity score and modified early warning score with rapid lactate level in blunt trauma patients. Eur J Emerg Med 2014, 21:199-205.

doi:10.1186/2197-425X-3-S1-A834

Cite this article as: Lee et al.: The usefulness of modified national early warning score with the age level in critically ill medical patients.

Intensive Care Medicine Experimental 2015 3(Suppl 1):A834.

\section{Submit your manuscript to a SpringerOpen ${ }^{\mathcal{O}}$ journal and benefit from:}

- Convenient online submission

- Rigorous peer review

- Immediate publication on acceptance

- Open access: articles freely available online

- High visibility within the field

- Retaining the copyright to your article

Submit your next manuscript at $\gg$ springeropen.com 